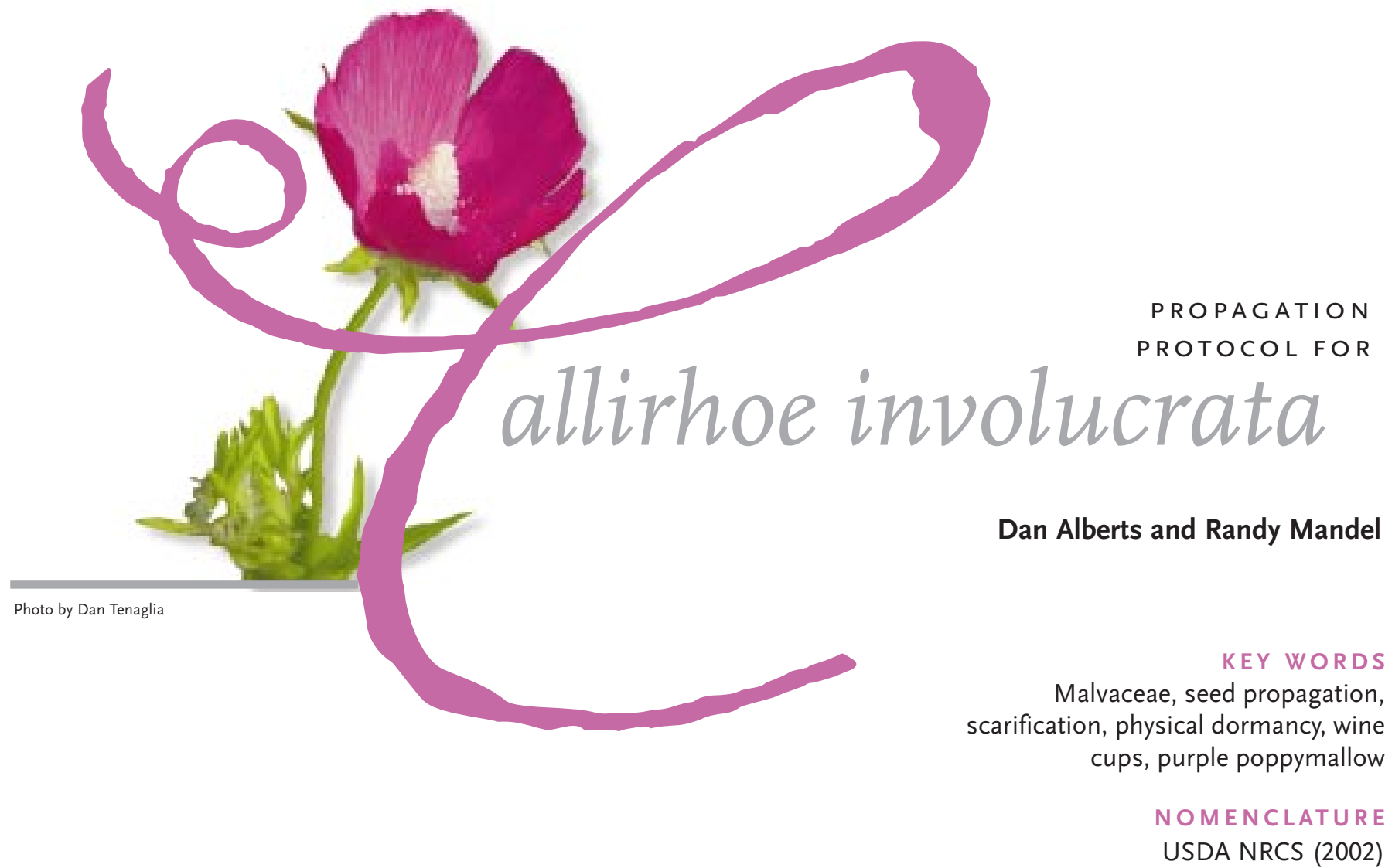

$\mathbf{R}$ ocky Mountain Native Plants Company (RMNP) is located in Rifle, Colorado. Currently, we are producing more than 2500000 native plants representing approximately 250 different species. RMNP produces and installs native plant materials from a wide range of habitats for restoration projects and for the growing landscaping industry that demands hardy, attractive native plant materials.

One species we grow, Callirhoe involucrata (Torr. \& Gray) Gray (Malvaceae), commonly known as wine cups or purple poppymallow, is a striking herbaceous plant that is rapidly gaining popularity in the landscape and horticultural industries. It is also widely used for roadside wildflower plantings and as a reliable, droughttolerant species for restoration projects because it readily establishes in disturbed areas with droughty soils.

One reason for its recent rise in popularity with landscapers and gardeners is its brightly colored flowers that are produced in profusion throughout the growing season. In southern portions of its range, this species can produce flowers from March to August. Callirhoe involu- crata can become a large, semi-erect to sprawling plant, making it suitable for large rock gardens, in mass plantings, or along garden walls and hillsides that utilize its rambling habit. A single plant can be 60 to $90 \mathrm{~cm}(2$ to $3 \mathrm{ft})$ across, and its height is typically 17 to $55 \mathrm{~cm}$ (8 in to 1.5 $\mathrm{ft})$. Leaves are palmate and are covered with fine hairs, which add to the character of the plant. Its numerous flowers are about 3.8 to $6 \mathrm{~cm}$ (1.5 to 2.5 in) across. Flowers have 5 satiny petals ranging in color from deep red to magenta or rose pink. Each petal has a splotch of white at the base, which highlights the numerous, pale yellow stamens borne on rose-pink filaments that are fused into a column and surround the stigma. White-flowered forms are also seen in nature. Because this species flowers over a prolonged period, mature fruits can be harvested several times over the summer and fall months. Each schizocarp ripens from green to brown and contains many hard seeds. The small seeds are prominently net veined on each side and have a short beak. Average seed weight is 160200 seeds/kg (72 800 seeds/lb), although this can vary by population.
Two botanical varieties are currently recognized. Callirhoe involucrata var. involucrata (Torr. \& Gray) Gray is found throughout Wyoming, North Dakota, and Minnesota south to northern Mexico in the western and central US as well as Michigan, Pennsylvania, and Virginia. Callirhoe involucrata var. lineariloba (Torr. \& Gray) Gray is found in the southwestern and southern Great Plains states and throughout Texas.

\section{SEED PROPAGATION}

Seeds have physical dormancy and should be scarified prior to planting. At RMNP, we use a hot-water scarification treatment. Using wet heat is an effective method for many small-seeded species with hard impermeable seed coats as it provides a rapid, uniform treatment, and results of the treatment can easily be seen within a few hours. Thickness of the seed coat may vary somewhat among sources, so it is a good idea to dissect a few seeds and examine the thickness of seed coats from each lot to help determine duration of the wet-heat treatment. 
Seeds are added to boiling water for only 5 to $10 \mathrm{~s}$ and then immediately transferred to a vat of cold water, which allows them to quickly cool and prevents embryo damage. The seeds imbibe in the cool water for $1 \mathrm{~d}$ and are ready for sowing without further treatment. We direct sow seeds to individual Ray Leach 164-ml $\left(10\right.$-in $\left.{ }^{3}\right)$ containers and lightly cover seeds with mulch approximately $1.5 \mathrm{~mm}$ deep. We use Scott's Metro Mix 360 (the Scott's Company, Marysville, Ohio) growing medium and fertigate with Peters $^{\circledR}$ Professional $^{\circledR}$ fertilizer 20:10:20 (20N: $\left.10 \mathrm{P}_{2} \mathrm{O}_{5}: 20 \mathrm{~K}_{2} \mathrm{O}\right)$ at the rate of 50 ppm twice weekly until seedlings develop a firm root plug. (We do not use heavy fertilizer application rates during the production of xeric species because heavy fertilization would produce seedlings that are not adapted to xeric planting sites.) Seedlings emerge within a few days after sowing, grow rapidly, and typically produce a firm root plug in as little as $1 \mathrm{mo}$. Callirhoe involucrata produces a fleshy tap root, which eventually becomes somewhat woody, so it is important to avoid over watering during production. Extra care is needed when extracting seedlings from containers for outplanting to ensure that the root is not damaged and to avoid transplant shock. Once well established after outplanting, this species is a hardy, drought-tolerant perennial that thrives in full, hot sun exposures, and sandy to gravelly soils. It also grows well in loamy garden soils if the soil is allowed to dry well between irrigations or if drainage is provided.

SUMMARY

A brief hot-water scarification is an effective treatment for breaking physical dormancy of C. involucrata seeds. It also works well for other hard-seeded members of the Malvaceae, such as desert globemallow (Sphaeralcea ambigua Gray) and mountain hollyhock (Iliamina rivularis [Dougl. ex Hook.] Greene), or other hard-seeded species that are difficult to scarify due to their small size and inability to withstand alternate scarification treatments. This species is a highly desirable native for the horticultural and landscape industries because, unlike many other perennials, it flowers for several months during the year. Its wide native range, hardiness, and drought-tolerant character make it an excellent choice for xeriscapes and native roadside plantings.

REFERENCE

USDA NRCS. 2002. The PLANTS database, version 3.5. URL: http://plants.usda.gov (accessed 5 Dec 2003). Baton Rouge (LA): The National Plant Data Center.

\section{AUTHOR INFORMATION}

Dan Alberts

Grower

Randy Mandel

Vice President | Senior Scientist

Rocky Mountain

Native Plants Company

3780 Silt Mesa Road

Rifle, CO 81650

native @rmnativeplants.com

rmnativeplants.com
Native Trees \& Shrubs in Small Containers

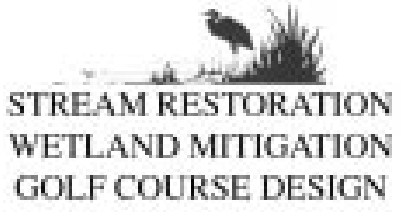

Alder. ..Aronia. ..Betla. . Carpinus. ..Callicarpa Chamaecyparis. . .Clethra. . .Cephalanthus

Cornus. . .Cyrilla. . .Franklinia. . .Fraxinus. . .llex Itea. . Lindera. . . Nyssa. ., Oxydendrum Rhododendron. . Quercus. . .Salix. . .Sambucus Taxodium. .. Viburnum

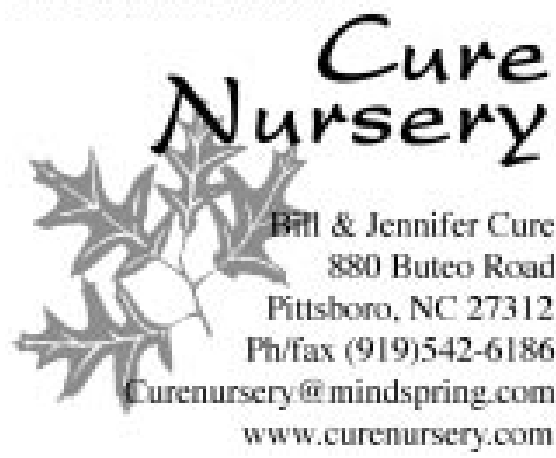

